\title{
Sabicea cinerea Aubl. (Rubiaceae): distilia e polinização em um fragmento de floresta Atlântica em Pernambuco, Nordeste do Brasil ${ }^{1}$
}

\author{
LUCIANA A.G. TEIXEIRA ${ }^{2,4}$ e ISABEL C. MACHADO ${ }^{3}$
}

(recebido: 26 de março de 2003; aceito: 20 de novembro de 2003)

\begin{abstract}
Sabicea cinerea Aubl. (Rubiaceae): distyly and pollination in a fragment of Atlantic rain forest in Pernambuco, Northeast of Brazil). The breeding system and pollination biology of Sabicea cinerea were studied at "Parque Estadual Dois Irmãos", a fragment of Atlantic forest, in Recife, State of Pernambuco, Brazil, from May/1998 to December/2000. Sabicea cinerea is a vine found in the forest border and which produces flowers throughout the year, with the flowering peak occurring in the dry season (September to February). It presents distylous, actinomorphic, tubular flowers, with white petals. Anthesis begins about $5.00 \mathrm{a} . \mathrm{m}$. nectar production continues until 4.00 p.m.; the daily mean average volume was $8.0 \mu \mathrm{L}$ and sugar concentration $24 \%$, in both floral morphs. Short-styled (thrum) flowers possess larger corolla and pollen grains in relation to the long-styled (pin) flowers, but there are no differences in the amount of grains between the morphs. Two species of hummingbird visited $S$. cinerea flowers, Phaethornis ruber, the main pollinator, and Amazilia sp., a nectar thief. Several species of Apidae, Anthophoridae and Halictidae bees, Hesperiidae and Nymphalidae butterflies and Syrphidae flies were also observed visiting Sabicea cinerea flowers. The self-incompatibility of the species was verified through experiments of controlled pollination in field; fruit set was observed only in the intermorph crossings. The occurrence of the sporophytic self-incompatibility was confirmed with the analysis of pollen tubes growth in both floral morphs. The efficiency in pollen transfer among the floral morphs is the main and more important function carried out by the pollinators in order to maintain the S. cinerea populations, mainly because it presents an obligatory xenogamous reproductive system.
\end{abstract}

Key words - heterostyly, hummingbird, pollination biology, Sabicea, self-incompatibility

RESUMO - (Sabicea cinerea Aubl. (Rubiaceae): distilia e polinização em um fragmento de floresta Atlântica em Pernambuco, Nordeste do Brasil). O estudo foi desenvolvido no Parque Estadual de Dois Irmãos, um fragmento de Floresta Atlântica, em Recife - PE, no período de maio/1998 a dezembro/2000. Sabicea cinerea é uma espécie lianescente encontrada na borda da mata, que produz flores por todo ano, com pico de floração na estação seca (setembro a fevereiro). Apresenta flores distílicas, actinomorfas, tubulosas, com pétalas brancas e antese iniciando por volta das 5:00 h, quando o néctar já está disponível; a produção de néctar estende-se até às 16:00 h. O volume médio diário de néctar foi de $8,0 \mu \mathrm{L}$ e a concentração média de açúcares, de $24 \%$, em ambos os morfos florais. As flores brevistilas possuem a corola e os grãos de pólen maiores em relação às flores longistilas, não havendo, entretanto, diferenças na quantidade dos grãos produzidos entre os dois morfos. Como visitantes florais, foram observados Phaethornis ruber, um dos principais polinizadores, e Amazilia sp., um pilhador. Além desses beija-flores, várias espécies de abelhas Apidae, Anthophoridae e Halictidae, borboletas Hesperiidae e Nymphalidae e moscas Syrphidae, visitavam as flores. A auto-incompatibilidade foi constatada através dos testes de polinização controlada, que resultaram na formação de frutos apenas nos cruzamentos intermorfo. A análise do crescimento dos tubos polínicos confirmou a ocorrência da auto-incompatibilidade esporofítica. A eficiência no transporte de pólen entre os morfos florais é a principal e mais importante função desempenhada pelos polinizadores para que ocorra a manutenção dos agrupamentos de indivíduos de S. cinerea, principalmente por esta espécie apresentar um sistema reprodutivo do tipo xenógamo obrigatório.

Palavras-chave - autoincompatibilidade, beija-flores, biologia da polinização, heterostilia, Sabicea

\section{Introdução}

A família Rubiaceae compreende cerca de 10.400 espécies distribuídas amplamente por todo o mundo, sendo a maioria encontrada na região dos trópicos,

1. Parte da dissertação de mestrado de L.A.G. Teixeira.

2. Universidade Federal de Pernambuco, CCB, Departamento de Botânica, Programa de Pós-Graduação em Biologia Vegetal, 50372-970 Recife, PE, Brasil.

3. Universidade Federal de Pernambuco, CCB, Departamento de Botânica, 50372-970 Recife, PE, Brasil.

4. Autor para correspondência: lagt@ufpe.br apresentando hábitos bastante variados como árvores, arbustos, lianas, ervas, epífitas e raras aquáticas (Mabberley 1993).

A heterostilia é um polimorfismo floral controlado geneticamente, havendo a formação de dois (distilia) ou três (tristilia) tipos de flores, sendo mais comum a ocorrência da distilia, com flores brevistilas e longistilas (Vuilleumier 1967, Ganders 1979, Barrett 1992, Kohn \& Barrett 1992). Os dois morfos florais são caracterizados pela diferença no comprimento dos estiletes e estames (hercogamia), diferenças no tamanho 
e na produção dos grãos de pólen e por possuírem, geralmente, um sistema de incompatibilidade heteromórfico em que os cruzamentos viáveis, com formação de frutos e sementes, ocorrem somente entre flores de diferentes morfos (Ganders 1979, Dulberger 1992, Kohn \& Barrett 1992). A família Rubiaceae é a que possui o maior número de gêneros com heterostilia dentre as 25 famílias de Angiospermas com representantes heterostílicos (Vuilleumier 1967, Andersson 1973, Ganders 1979, Barrett 1992, Kohn \& Barrett 1992).

Vários estudos feitos com espécies heterostílicas de Rubiaceae enfocam a ocorrência de autoincompatibilidade (Keegan et al. 1979, Hicks et al. 1985, Feinsinger \& Busby 1987, Murray 1990, Passos \& Sazima 1995, Pailler \& Thompson 1997, Ree 1997, Castro \& Oliveira 2002), existindo também alguns casos de autocompatibilidade dentro da família (Sobrevila et al. 1983, Richards \& Koptur 1993, Riveros et al. 1995). Estes trabalhos e Hamilton (1990), Percy \& Cronk (1997), Machado \& Loiola (2000), Ortiz et al. (2000) de uma forma geral, mencionam a variedade de animais que visitam as flores de Rubiaceae como abelhas, borboletas, beija-flores, mariposas e moscas. Neste estudo apresentamos a ocorrência de heterostilia do tipo distílica e a polinização de Sabicea cinerea, uma espécie lianescente de borda de mata, em um fragmento de Floresta Atlântica de Pernambuco. São apresentados dados sobre o sistema reprodutivo e a importância dos polinizadores para a manutenção do polimorfismo floral e sucesso reprodutivo dos indivíduos brevistílicos e longistílicos de Sabicea cinerea.

\section{Material e métodos}

As observações de campo foram realizadas no Parque Estadual de Dois Irmãos, fragmento de mata Atlântica de Pernambuco, localizado no município de Recife, estado de

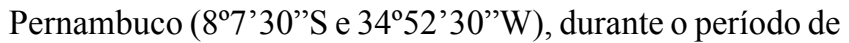
maio/1998 a dezembro/2000. O Parque Estadual de Dois Irmãos está localizado a noroeste da cidade do Recife, com uma área de, aproximadamente, 370 ha. O clima é do tipo As', tropical costeiro, quente e úmido, com temperaturas médias mensais superiores a $23^{\circ} \mathrm{C}$, apresentando um período de alta umidade entre os meses de março e agosto, com precipitações máximas ocorrendo em junho e julho (Coutinho et al. 1998).

As informações sobre a morfologia das flores, duração, horário e seqüência da antese, receptividade do estigma, número de flores abertas por inflorescência, além da disponibilidade de néctar e pólen, foram registradas em indivíduos agrupados em quatro manchas distintas na borda da mata e separadas entre si, duas de flores brevistilas e duas de flores longistilas. As áreas ocupadas pelos agrupamentos foram medidas, uma vez que não foi possível a contagem do número total de indivíduos por morfo. De acordo com as classificações de Gentry (1974) e Newstron et al. (1994), foi determinado o padrão de floração da espécie.

O número total de óvulos por ovário foi verificado sob microscópio estereoscópico e a contagem do número de grãos de pólen por antera, foi feita utilizando-se câmara de Neubauer, segundo a metodologia proposta por Maêda (1985), posteriormente, foi efetuada a razão pólen/óvulo (Cruden 1977) e a viabilidade dos grãos de pólen foi determinada através da técnica de coloração de Radford et al. (1974), utilizando-se 10 flores por morfo. Os números de óvulos, grãos de pólen, a razão pólen/óvulo e o comprimento das corolas foram comparados pelo Teste $\mathrm{t} e$ a freqüência de viabilidade polínica foi verificada através do qui-quadrado (Sokal \& Rohlf 1996). A análise da morfometria polínica, nos dois morfos, foi realizada utilizando-se a técnica de acetólise (Erdtman 1966), sendo medidos os diâmetros polar e equatorial de 25 grãos, provenientes de cinco flores por morfo, distribuídos ao acaso em 10 lâminas e os resultados comparados através da análise pelo Coeficiente de Variação (CV). As medidas das alturas dos estigmas, das anteras e o tamanho dos grãos de pólen foram comparados estatisticamente pelo teste $U$ (Mann-Whitney) (Sokal \& Rohlf 1996).

Para medir a concentração de açúcares e o volume do néctar foram utilizados, respectivamente, refratômetro de bolso e micro-seringas ( $\mu \mathrm{L})$ em 10 flores, cinco de cada morfo, ensacadas no dia anterior à antese, no período das 6:00 h até às 16:00 h, em intervalos de duas horas entre uma medida $\mathrm{e}$ outra. A receptividade do estigma foi determinada em três flores de cada morfo, em campo, através da reação com peróxido de hidrogênio (Zeisler 1938).

Para análise do sistema reprodutivo de Sabicea cinerea, foram feitos experimentos manuais de autopolinização e polinização intermorfos (Radford et al. 1974), sendo utilizados botões em fase de pré-antese. O controle foi feito a partir da marcação de flores de cada morfo e, posteriormente, contados os números de frutos e sementes formados. A verificação do crescimento do tubo polínico foi feita através de cruzamentos em laboratório, utilizando-se flores mantidas em caixas de acrílico com ágar-ágar $2 \%$. As flores polinizadas foram fixadas em FAA 70\%, em intervalos de 8, 12, 24 e $48 \mathrm{~h}$ e, posteriormente foram tratadas com $\mathrm{NaOH}$, coradas com azul de anilina e analisadas em microscópio de fluorescência (Martin 1959).

Foram feitas observações, documentadas com fotografias e filmagem em vídeo, sobre o comportamento dos visitantes florais, registrando-se a freqüência, a duração e o horário das visitas. A freqüência dos visitantes florais foi verificada ao longo de 50 horas em cinco dias não consecutivos, sendo registrados o número de visitas em cada hora (senso). Insetos visitantes das ordens Himenoptera, Diptera e Lepidoptera foram coletados e montados para identificação. Os beija-flores foram identificados através das 
fotografias e filmagens, por comparação, usando-se bibliografia especializada (Sick 1985, Grantsau 1989). Os espécimes-testemunho das abelhas, moscas e mariposas diurnas encontram-se depositados na coleção de insetos polinizadores do Laboratório de Biologia Floral e Reprodutiva (Departamento de Botânica-UFPE). O material testemunho de $S$. cinerea está depositado no herbário do Departamento de Botânica da UFPE (UFP n. 27.893 e 27.895).

\section{Resultados}

Sabicea cinerea é uma liana cujos indivíduos formam manchas encontradas exclusivamente nas bordas da mata, principalmente em locais bastante ensolarados. Os ramos flexíveis podem ocupar diferentes estratos da mata, ocorrendo em alturas que variam de $50 \mathrm{~cm}$ a $5 \mathrm{~m}$, dependendo do porte (arbustivo ou arbóreo) da espécie suporte. A caracterização morfológica das flores indicou a ocorrência de heterostilia do tipo distílica (figura 1), com dois agrupamentos de indivíduos brevistílicos e dois de indivíduos longistílicos, os quais ocuparam áreas de $60 \mathrm{~m}^{2}$ e $240 \mathrm{~m}^{2}$, respectivamente, sendo encontrada uma proporção de 1:4 entre os morfos.

A produção de flores ocorreu durante todo o ano com um pico na estação de baixa pluviosidade (de setembro até o final de fevereiro). Durante o período de pico de floração, os agrupamentos brevistílicos e longistílicos apresentaram cerca de 15 e 60 flores abertas por dia, respectivamente, sendo os longistílicos, maiores em área total ocupada pelos indivíduos. Foi verificado que, principalmente nos meses de alta pluviosidade (março a julho) e mínima produção de flores, os agrupamentos apresentaram alta reprodução vegetativa. As inflorescências são cimosas axilares, dispostas lateralmente, com cerca de 15 a 20 flores densamente agrupadas em glomérulos, abrindo de uma a três flores por dia. As flores são brancas, tubulosas, actinomorfas, pentâmeras, apresentando muitos pêlos em toda face interna e externa da corola. O comprimento médio das flores brevistilas e longistilas é de $30 \mathrm{~mm}$ e $25 \mathrm{~mm}$ ( $\mathrm{n}=$ 10), respectivamente, apresentando diferença significativa.

$\mathrm{O}$ androceu é formado por cinco estames férteis, com anteras de deiscência longitudinal, filetes epipétalos, apresentando dois níveis de altura no tubo floral (figura 1). O tamanho das anteras, o número de grãos de pólen produzidos por flor e a razão pólen/óvulo não apresentaram diferenças significativas entre os dois morfos florais, entretanto, a viabilidade polínica entre os morfos foi significativamente diferente $\left(\mathrm{X}^{2}=49.228\right.$, $\mathrm{p}<0,001$ ) (tabela 1). Os grãos de pólen das duas formas florais são triporados, apresentando diferenças significativas nos diâmetros polar e equatorial, sendo maiores nas flores brevistilas (tabela 2).

O gineceu é composto por ovário ínfero, pentacarpelar, pentalocular com muitos óvulos, com estilete terminando em um estigma pentalobular, com papilas por toda a superfície. As alturas do estigma das flores longistilas e das anteras das flores brevistilas foram significativamente diferente, enquanto que não foi observada diferença significativa em relação às alturas do estigma das flores brevistilas e das anteras das flores longistilas (tabela 3 ).

A abertura das flores teve início por volta das 5:00 h, com a distensão lenta dos lobos da corola, ocasião em que as anteras encontraram-se deiscentes e os lóbulos do estigma um pouco unidos, porém já receptivos. Por volta das 6:00 h as flores já estavam completamente abertas, com os lobos da corola reflexos. O nectário, em forma de disco, localiza-se no ápice do ovário (figura 1). A produção de néctar foi contínua, ocorrendo desde a fase de pré-antese até às 16:00 h. O volume total acumulado de néctar durante o dia foi de ca. $20 \mu \mathrm{L}$

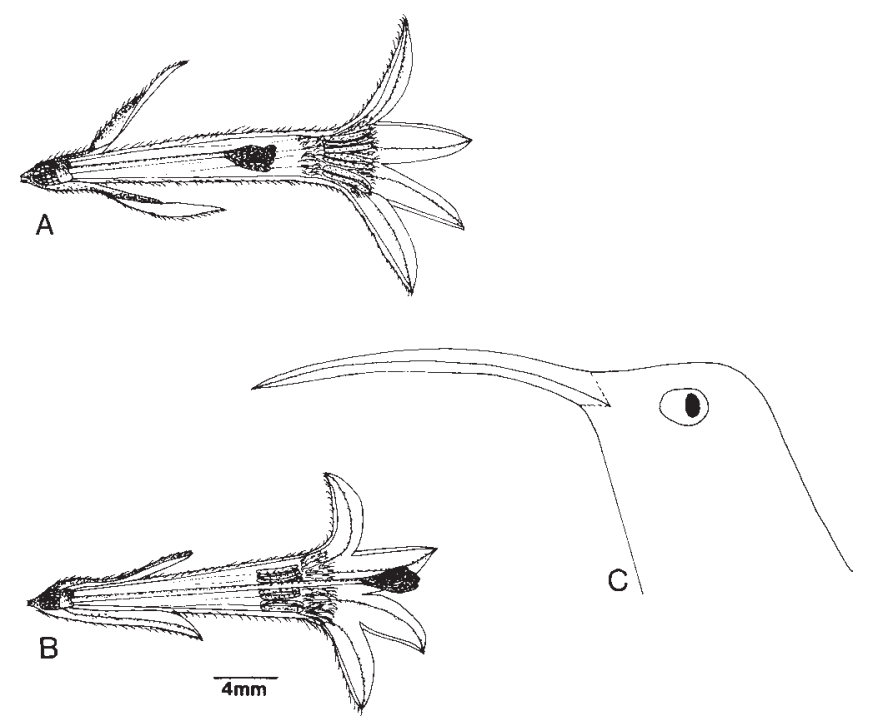

Figura 1. Corte longitudinal das flores de Sabicea cinerea, tendo sido retirada uma pétala, mostrando flor brevistila (A), flor longistila (B) e esquema da cabeça de Phaethornis ruber (C), ilustrando a relação entre o comprimento dos estiletes e as alturas das anteras com o bico do beija-flor.

Figure 1. Longitudinal section of flowers of Sabicea cinerea, in this case, a petal was cut. The short-styled (A) and longstyled (B) flowers and drawing of head of Phaetornis ruber (C) show the relationship between styles lenght and anthers height with beak of hummingbird. 
Tabela 1. Número de grãos de pólen por antera $(\mathrm{G} / \mathrm{A})$ e por flor $(\mathrm{G} / \mathrm{F})$, óvulos por flor $(\mathrm{O} / \mathrm{F})$, razão pólen/óvulo $(\mathrm{P} / \mathrm{O})$ e viabilidade polínica (VP) de Sabicea cinerea $(\mathrm{N}=10$; * estatisticamente diferentes).

Table 1. Pollen grains per anther $(\mathrm{G} / \mathrm{A})$ and per flower $(\mathrm{G} / \mathrm{F})$, ovules per flower $(\mathrm{O} / \mathrm{F})$, pollen/ovule ratio $(\mathrm{P} / \mathrm{O})$ and pollen viability (VP) of Sabicea cinerea $(\mathrm{N}=10$; * statistically different).

\begin{tabular}{lccccc}
\hline Morfos & $\mathrm{G} / \mathrm{A}$ & $\mathrm{G} / \mathrm{F}$ & $\mathrm{O} / \mathrm{F}$ & $\mathrm{P} / \mathrm{O}$ & $\mathrm{VP*}$ \\
\hline Flores brevistilas & 26.700 & 133.500 & 265,8 & 502,2 & $88,6 \%$ \\
Flores longistilas & 26.400 & 132.000 & 272,5 & 484,4 & $89,4 \%$ \\
\hline
\end{tabular}

e a concentração de açúcares em torno de $24 \%$, para ambos os morfos florais. O murchamento das flores ocorreu durante a noite e a abcisão se deu no começo da manhã do dia seguinte à antese, permanecendo na inflorescência apenas as sépalas envolvendo o ovário. Foi verificada uma maior produção de néctar na primeira parte da manhã, com a diminuição do volume no decorrer do dia, tendo o mesmo acontecido com a concentração de açúcares, nas flores brevistilas e longistilas (figura 2).

Os resultados dos testes de polinização manual mostraram que houve sucesso na formação de frutos apenas nos cruzamentos intermorfo e que a média de frutos formados em condições naturais foi de $70 \% \mathrm{e}$ $50 \%$ em morfos brevistílicos e longistílicos, respectivamente (tabela 4). A análise do crescimento do tubo polínico mostrou que, nos testes de autopolinização manual, tanto nas flores brevistilas quanto nas flores longistilas, a reação de incompatibilidade ocorreu no estigma, entre 12 e 24 horas após a polinização. Nos cruzamentos intermorfo, em que as flores longistilas foram doadoras de pólen, verificou-se que os tubos polínicos penetraram no ovário com 12 horas, enquanto que as flores doadoras de pólen foram as brevistilas foi verificado que os tubos polínicos alcançaram o ovário entre 12 e 24 horas. A penetração dos tubos nos óvulos, tanto das flores longistilas quanto das brevistilas, foi observada entre 24 e 36 horas após a polinização. No cruzamento entre flores longistílicas de agrupamentos distintos verificou-se que os tubos polínicos cresceram até, aproximadamente, a metade do estilete, sendo interrompidos 12 horas após a polinização, com a formação de "plugs" de calose. Os cruzamentos entre flores brevistilas, tanto para verificação de formação de frutos, quanto para análise do crescimento do tubo polínico, não puderam ser feitos devido ao corte de um dos agrupamentos durante os experimentos.

As flores de Sabicea cinerea foram visitadas por beija-flores, abelhas, borboletas, mariposas diurnas, moscas (tabela 5). As primeiras visitas às flores eram feitas pelos beija-flores Phaethornis ruber (figura 3), entre 5:00 h e 5:30 h, período em que ainda estavam abrindo, mas já produzindo néctar. As visitas se prolongavam até o final do dia $(16: 00 \mathrm{~h})$ quando não havia mais néctar, durante todo ano. A outra espécie de beija-flor, Amazilia sp. foi observada visitando apenas flores de um dos agrupamentos longistílicos. Durante o pico de produção de flores, este beija-flor ficava pousado em um ramo próximo às flores longistilas, expulsando outros beija-flores da área.

As espécies de moscas foram observadas pilhando néctar, acumulado no tubo de flores longistilas localizadas por baixo da folhagem e próximas ao solo, entre 9:00 e 11:30 h, durante o pico de floração. As

Tabela 2. Medidas dos diâmetros polar e equatorial dos grãos de pólen triporados de Sabicea cinerea.

Table 2. Measurements of polar and equatorial diameter of the triporates pollen grains of Sabicea cinerea.

Grandezas

Diâmetro Polar (P):

Flores brevistilas

Flores longistilas

Teste

Faixa de variação $(\mu \mathrm{m})$

27,5-32,5

$30 \pm 0,26$

$\mathrm{X} \pm \mathrm{Sx}(\mu \mathrm{m})$

CV $(\%)$

$\begin{array}{ll}22,5-27,5 & U=2,5 ; \mathrm{p}<0,001 \\ 25,6 \pm 0,29 & \\ 5,8 & \end{array}$

$22,5-27,5$

5,8

Diâmetro equatorial (E):

\begin{tabular}{lccc}
\hline Faixa de variação $(\mu \mathrm{m})$ & $28,7 \pm 32,5$ & $23,7-30$ & $U=25.000 ; \mathrm{p}<0,001$ \\
$\mathrm{x} \pm \mathrm{Sx}(\mu \mathrm{m})$ & $30,4 \pm 0,23$ & $27,3 \pm 0,26$ & \\
$\mathrm{CV}(\%)$ & 3,9 & 4,8 & \\
$\mathrm{P} / \mathrm{E}$ & 0,98 & 0,93 & \\
\hline
\end{tabular}


Tabela 3. Medidas (mm) das características florais dos dois morfos de Sabicea cinerea $(\mathrm{N}=10)$.

Table 3. Morphometrics of floral traits of both Sabicea cinerea morphs $(\mathrm{N}=10)$.

\begin{tabular}{lccc}
\hline & Comprimento da corola & Altura do estigma & Altura das anteras \\
\hline Brevistila (x) & $27,7 \pm 0,65$ & $14,6 \pm 0,27$ & $18,0^{\mathrm{b}} \pm 0,37$ \\
Longistila (x) & $24,2 \pm 0,63$ & $19,6^{\mathrm{a}} \pm 0,34$ & $14,8 \pm 0,44$ \\
Teste & $\mathrm{t}=3,86 ;$ g.l. $=18 ; \mathrm{P}<0,01$ & avs. $\mathrm{U}=84 ; \mathrm{P}<0,05$ & \\
\hline
\end{tabular}

borboletas Heliconius sp. (figura 4) e as mariposas diurnas Urbanus proteus e Calpodes ethlius foram observadas apenas na época de máxima produção de flores, apresentando o mesmo comportamento na coleta de néctar, em ambos os morfos florais, começando as visitas por volta das 8:00 h e com menor freqüência em torno de 11:30 h. Em vôo lento, pousavam nos lobos da corola e, ao introduzirem a espirotromba, tocavam o estigma e as anteras.

Sete espécies de abelhas foram registradas visitando as flores de Sabicea cinerea, sendo Exaerete smaragdina (figura 5) uma das mais observadas, começando a coleta de néctar por volta das 8:30 h nos dois morfos florais e contactando as estruturas reprodutivas florais com a língua. Indivíduos de Euglossa cordata foram vistos, muito freqüentemente, entre 9:00 e 13:00 h (figura 6), tocando as estruturas reprodutivas

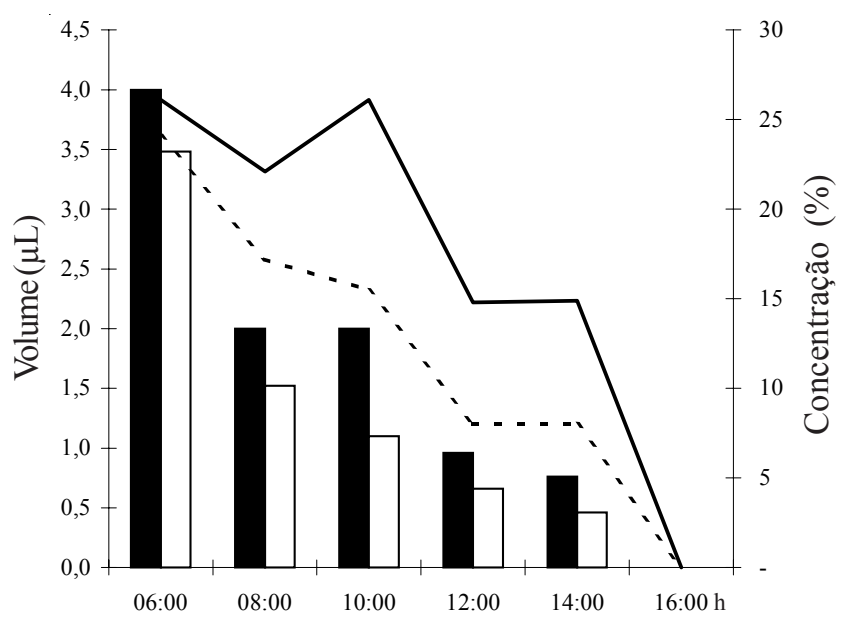

Figura 2. Médias do volume (barras) e da concentração de açúcares (linhas) no néctar em flores brevistilas e longistilas $(\mathrm{n}=20)$ de Sabicea cinerea $\mathbf{\square}-=$ Flores longistilas; $\square---=$ Flores brevistilas.

Figure 2. Means of volume (bars) and sugar concentration (lines) nectar in short-styled and long-styled flowers $(\mathrm{n}=20)$ of Sabicea cinerea . $\mathbf{\square -}=$ Long-styled flowers; $\square----=$ Shortstyled flowers ao coletarem néctar de flores brevistilas e longistilas, sendo considerados polinizadores. Os indivíduos de Eulaema nigrita e Melipona scutellaris foram observados raras vezes, coletando sempre néctar, da mesma maneira e no mesmo período do dia que Euglossa cordata, sendo vistos em flores de ambos os morfos florais. Epicharis cf. fasciata foi observada visitando flores de ambos os morfos florais, principalmente no período entre 9:00 e 13:00 h. Durante a coleta de néctar nas flores longistilas, pousadas nos lobos da corola, as abelhas introduziam a língua no tubo floral e o contato com a superfície estigmática era feito com o aparelho bucal, região do clípeo, labro e mandíbulas, enquanto que nesse mesmo local possivelmente ficavam aderidos os grãos de pólen das flores brevistilas. Xylocopa suspecta (figura 7) e Pseudoaugochloropsis sp. (figura 8), coletavam néctar na base externa da corola, sendo observadas durante todo o ano e em horários variados do dia. Trigona fulviventris coletava apenas pólen nas flores brevistilas,

Tabela 4. Resultado dos experimentos para verificação do sistema reprodutivo em Sabicea cinerea $(*$ doador de pólen; ** receptor de pólen).

Table 4. Result of experiments to verify the breeding system of Sabicea cinerea (* pollen donor; ** pollen receiver).

\begin{tabular}{lccc}
\hline Tratamentos & $\begin{array}{c}\text { Flores } \\
\text { (n) }\end{array}$ & $\begin{array}{c}\text { Frutos/ } \\
\text { Sementes } \\
\text { (n) }\end{array}$ & $\begin{array}{c}\text { Sucesso } \\
(\%)\end{array}$ \\
\hline $\begin{array}{l}\text { Autopolinização manual } \\
\text { (flores brevistilas) }\end{array}$ & 10 & 0 & 0 \\
$\begin{array}{c}\text { Autopolinização manual } \\
\text { flores longistilas) }\end{array}$ & 10 & 0 & 0 \\
$\begin{array}{l}\text { Polinização cruzada } \\
\text { fl. brevistila* vs. fl. longistila** }\end{array}$ & 10 & $5 / 1380$ & 50 \\
$\begin{array}{l}\text { fl. longistila* } v s . \text { fl. brevistila*** } \\
\text { Controle } \\
\text { fl. brevistila }\end{array}$ & 11 & $6 / 1685$ & 54 \\
fl. longistila & 10 & $7 / 1641$ & 70 \\
\hline & 10 & $5 / 1160$ & 50 \\
\hline
\end{tabular}


Tabela 5. Visitantes florais, frequência, recompensa coletada e resultado da visita em Sabicea cinerea. MF = muito freqüente $\left(\geq 4\right.$ visitas.hora $\left.{ }^{-1}\right), \mathrm{F}=$ freqüente $\left( \pm 3\right.$ visitas.hora $\left.{ }^{-1}\right), \mathrm{PF}=$ pouco freqüente $\left( \pm 2\right.$ visitas.hora $\left.{ }^{-1}\right), \mathrm{R}=$ raro $\left(\leq 1\right.$ visita.hora $\left.{ }^{-1}\right)$, $\mathrm{P}=$ pólen, $\mathrm{N}=$ néctar, $\mathrm{PO}=$ polinização, $\mathrm{PI}=$ pilhagem.

Table 5. Floral visitors, frequency, collected reward and the visit result of Sabicea cinerea. $\mathrm{MF}=$ very frequent $\left(\geq\right.$ visits.hour $\left.^{-1}\right)$, $\mathrm{F}=$ frequent $\left( \pm 3\right.$ visits.hour $\left.r^{-1}\right), \mathrm{LF}=$ less frequent $\left( \pm 2\right.$ visits.hour $\left.^{-1}\right), \mathrm{R}=$ rare $\left(\leq 1\right.$ visit.hour $\left.{ }^{-1}\right), \mathrm{P}=$ pollen, $\mathrm{N}=$ nectar, $\mathrm{PO}=$ pollination, $\mathrm{PI}=$ robber.

\begin{tabular}{|c|c|c|c|c|c|}
\hline Visitantes & $\begin{array}{c}\text { Flores } \\
\text { longistilas }\end{array}$ & $\begin{array}{c}\text { Flores } \\
\text { brevistilas }\end{array}$ & Freqüência & $\begin{array}{l}\text { Recomp. } \\
\text { coletada }\end{array}$ & $\begin{array}{c}\text { Resultado } \\
\text { da visita }\end{array}$ \\
\hline \multicolumn{6}{|l|}{ Himenoptera } \\
\hline \multicolumn{6}{|l|}{ Anthophoridae } \\
\hline Epicharis cf. fasciata & + & + & $\mathrm{PF}$ & $\mathrm{N}$ & $\mathrm{PO}$ \\
\hline Xylocopa $($ Neoxylocopa) suspecta & + & + & MF & $\mathrm{N}$ & PI \\
\hline \multicolumn{6}{|l|}{ Apidae } \\
\hline Euglossa cordata & + & + & $\mathrm{F}$ & $\mathrm{N}$ & $\mathrm{PO}$ \\
\hline Eulaema nigrita & + & + & $\mathrm{R}$ & $\mathrm{N}$ & $\mathrm{PO}$ \\
\hline Exaerete smaragdina & + & + & MF & $\mathrm{N}$ & PO \\
\hline Melipona scutellaris & + & + & $\mathrm{R}$ & $\mathrm{N}$ & PO \\
\hline Trigona fulviventris & - & + & MF & $\mathrm{P}$ & PI \\
\hline \multicolumn{6}{|l|}{ Halictidae } \\
\hline Pseudaugochloropsis sp. & + & + & MF & $\mathrm{N}$ & PI \\
\hline \multicolumn{6}{|l|}{ Diptera } \\
\hline \multicolumn{6}{|l|}{ Syrphidae } \\
\hline Ornidia obesa & + & - & $\mathrm{PF}$ & $\mathrm{N}$ & PI \\
\hline sp. 1 & + & - & $\mathrm{PF}$ & $\mathrm{N}$ & PI \\
\hline sp. 2 & + & - & $\mathrm{PF}$ & $\mathrm{N}$ & PI \\
\hline \multicolumn{6}{|l|}{ Lepidoptera } \\
\hline \multicolumn{6}{|l|}{ Hesperiidae } \\
\hline Calpodes ethlius & + & + & MF & $\mathrm{N}$ & $\mathrm{PO}$ \\
\hline Urbanus proteus & + & + & MF & $\mathrm{N}$ & $\mathrm{PO}$ \\
\hline \multicolumn{6}{|l|}{ Nymphalidae } \\
\hline Heliconius sp. & + & + & $\mathrm{F}$ & $\mathrm{N}$ & $\mathrm{PO}$ \\
\hline \multicolumn{6}{|l|}{ Aves } \\
\hline \multicolumn{6}{|l|}{ Trochilidae } \\
\hline Amazilia sp. & + & - & MF & $\mathrm{N}$ & PI \\
\hline Phaethornis ruber & + & + & MF & $\mathrm{N}$ & PO \\
\hline
\end{tabular}

no começo da manhã, entre $6: 30$ e 8:00 h. Ao pousar nos lobos da corola, com as pernas anteriores coletava pólen e, ainda na flor, com o auxílio das pernas medianas, transferia para as pernas posteriores.

\section{Discussão}

Os indivíduos de Sabicea cinerea produzem flores durante o ano todo, apresentando padrão de floração do tipo contínuo (Newstron et al. 1994), com um pico na estação de baixa pluviosidade e escassez de flores na estação chuvosa. Outras espécies de Rubiaceae apresentam esse padrão contínuo de floração como Cephaelis tomentosa (Aubl.) Vahl, Hamelia patens Jacq. (Newstron et al. 1994) e Manettia luteo-rubra Benth. (Passos \& Sazima 1995). Os agrupamentos brevistílicos e longistílicos de $S$. cinerea ocorreram na razão de $1: 4$, sendo a maior área ocupada pelos indivíduos longistílicos, indicando a ocorrência de anisopletia ao nível individual. Segundo Ganders (1979) e Barrett (1992), dois fatores podem influenciar as espécies distílicas no aumento, em proporções desiguais, 

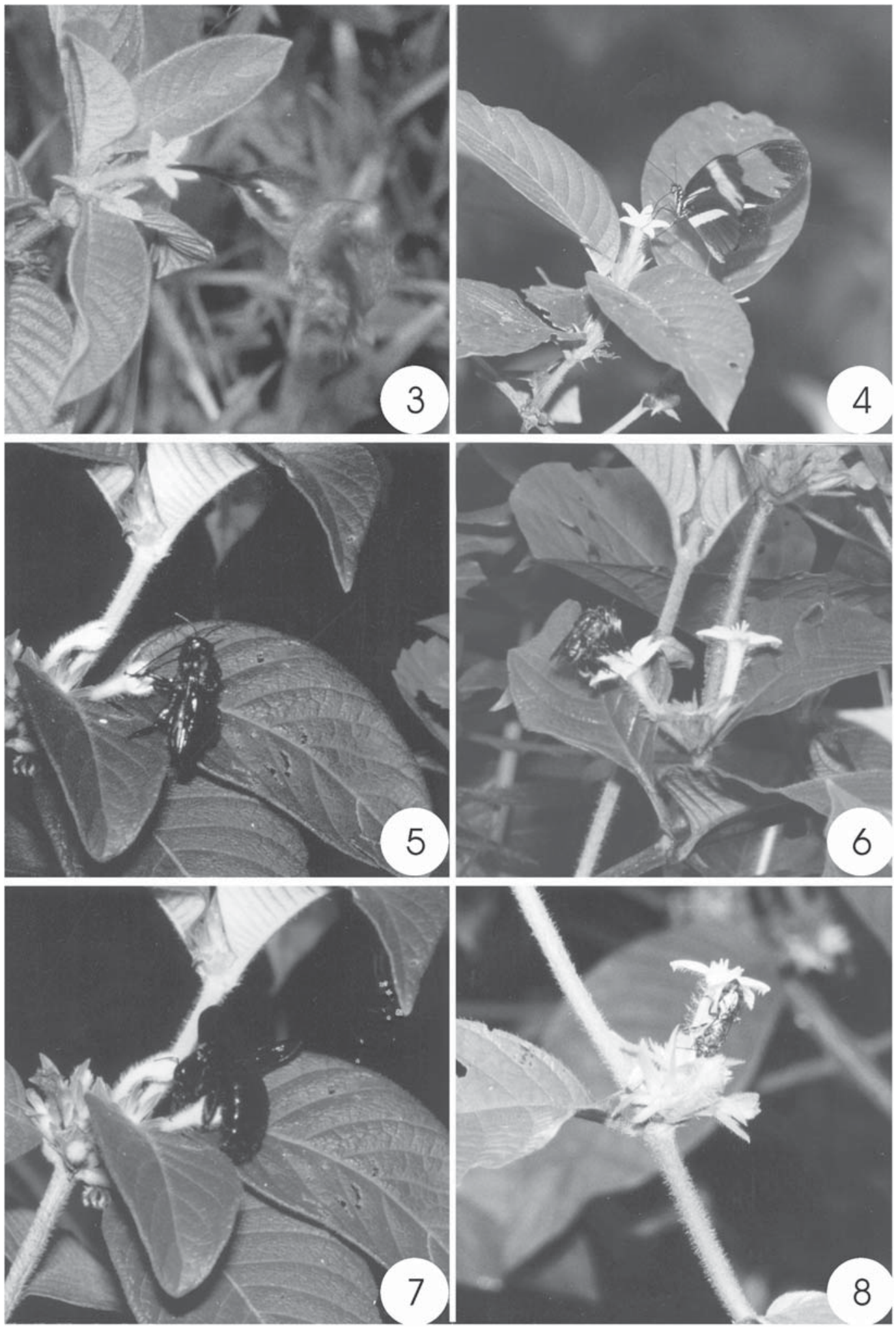

Figuras 3-8. Polinizadores de Sabicea cinerea coletando néctar de flores longistilas. 3. Phaethornis ruber. 4. Heliconius sp. 5. Exaerete smaragdina. 6. Euglossa cordata introduzindo a língua no tubo floral. 7-8. Abelhas pilhadoras coletando néctar por fora do tubo floral. 7. Xylocopa suspecta. 8. Pseudoaugochloropsis sp.

Figures 3-8. Pollinators of Sabicea cinerea collecting nectar of long-styled flowers. 3. Phaethornis ruber. 4. Heliconius sp. 5. Exaerete smaragdina. 6. Euglossa cordata introducing its tongue in the floral tube. 7-8. Robber bees collecting nectar on the outside of floral tube. 7. Xylocopa suspecta. 8. Pseudoaugochloropsis sp. 
de um dos morfos florais: a produção de novos indivíduos através da reprodução vegetativa, relatada aqui para $S$. cinerea, ou por haver a formação de frutos e sementes decorrentes de flores autopolinizadas. A variação interpopulacional na razão dos morfos, com predominância de indivíduos longistílicos foi descrita para Palicourea petiolaris H.B.K. na Venezuela (Sobrevila et al. 1983), onde essa variação ocorreu devido à presença de autocompatibilidade, não sendo registrada reprodução vegetativa.

A heterostilia do tipo distílica é registrada, por vários autores, para inúmeras espécies da família Rubiaceae, como no gênero Sabicea por Vuilleumier (1967) e por Ganders (1979), assim como em Oldenlandia, Hedyotis, Bouvardia, Rudgea, Psychotria, Borreria, Manettia, Palicourea, Stipularia (Vuilleumier 1967, Barrett \& Richards 1990). As flores de S. cinerea apresentaram diferenças morfométricas que são encontradas na maioria das espécies heterostílicas, tais como flores brevistilas possuindo maior comprimento e grãos de pólen com maior diâmetro, em comparação com as flores longistilas. A diferença no comprimento das flores foi observada em Palicourea fendleri Standl. e P. petiolaris H.B.K. (Sobrevila et al. 1983), Guettarda scabra L. (Richards \& Koptur 1993), Manettia luteo-rubra Benth. (Passos \& Sazima 1995), Gaertnera vaginata Lam. (Pailler \& Thompson 1997) e Palicourea padifolia (Roem. \& Schult.) C.M. Taylor \& Lorence (Ree 1997, Contreras \& Ornelas 1999). Com relação às diferenças no diâmetro dos grãos de pólen entre os morfos florais, Jung-Mendaçolli \& Melhem (1995) estudaram espécies de nove gêneros de Rubiaceae e verificaram que, de uma forma geral, as flores brevistilas apresentaram grãos maiores. Estas diferenças morfométricas entre os grãos de pólen de flores distílicas foram justificadas por Darwin (1896) como sendo necessárias para que houvesse um maior armazenamento de reservas nos grãos de flores brevistilas para o crescimento do tubo polínico nos longos estiletes das flores longistilas, sendo esta hipótese, porém, questionada por Ganders (1979) e Dulberger (1992). A produção de grãos de pólen, geralmente, é maior nas flores longistilas e essa diferença existe como uma forma de compensar o fluxo assimétrico de pólen entre as formas florais, dado que o estigma de flores brevistilas, estando dentro do tubo da corola, estaria menos exposto, havendo necessidade das flores longistilas produzirem maior quantidade de grãos (Ganders 1979, Dulberger 1992). As flores de $S$. cinerea, entretanto, produziram grãos de pólen em quantidades equivalentes, podendo esse fato ocorrer em algumas espécies heterostílicas (Dulberger 1992). Contudo, devemos levar em consideração que os indivíduos longistílicos ocuparam uma área maior e dessa forma, houve mais flores abertas durante os dias e, conseqüentemente, mais pólen disponível para a reprodução.

Espécies distílicas apresentam hercogamia recíproca quando as alturas dos estigmas e anteras se equivalem nos morfos opostos (Vuilleumier 1967, Ganders 1979, Barrett 1992). Entretanto, existem espécies em que essa equivalência não é exata, como foi o caso para $S$. cinerea, que apresentou diferença significativa entre o comprimento do estilete das flores longistilas e a altura das anteras das flores brevistilas (Hamilton 1990, Dulberger 1992). Apesar das flores brevistilas possuirem o tubo floral maior, com anteras apresentando filetes epipétalos, teoricamente a equivalência com a porção estigmática das flores longistilas deveria ocorrer, mas os resultados indicaram a existência de um dimorfismo mais acentuado no comprimento dos estiletes, com flores longistilas possuindo a região do estigma um pouco superior à altura das anteras das flores brevistilas (Richards \& Koptur 1993).

As flores heterostílicas são mencionadas como polinizadas por vários tipos de insetos, principalmente abelhas, mas também por moscas, mariposas, borboletas, besouros e beija-flores, não havendo registros para morcegos (Ganders 1979, Richards \& Koptur 1993, Castro \& Oliveira 2002). Sabicea cinerea apresenta flores que, através da análise das características morfológicas, não foi possível enquadrá-las claramente em nenhum tipo de síndrome floral sugerido por Faegri \& Pij1 (1979), Endress (1994) ou Proctor et al. (1996), recebendo uma variedade de animais visitantes incluindo algumas espécies de moscas, abelhas, borboletas, mariposas diurnas e beijaflores que, de uma forma geral, visitam flores tubulosas e têm o néctar como recurso primário. Entretanto, a relação entre a concentração de açúcares do néctar e o tipo de polinizador é importante (Percival 1965, Baker 1975), pois as flores polinizadas por beija-flores geralmente possuem concentração variando em torno de $20 \%$ e $24 \%$, diferentemente das flores polinizadas por abelhas, que caracteristicamente apresentam médias de concentração entre $30 \%$ e $48 \%$ (Proctor et al. 1996). As flores de $S$. cinerea, em ambos os morfos, produziram néctar com uma média de concentração de açúcares em torno de $24 \%$, apresentando picos de até $27 \%$ nas flores longistilas, indicando uma variação relacionada, principalmente, 
com um sistema de polinização generalista (Herrera 1996, Waser et al. 1996). A polinização por beija-flores e/ou outros insetos parece comum na família e tem sido relatada para várias espécies de Rubiaceae (Bawa \& Beach 1983, Sobrevila et al. 1983, Feinsinger \& Busby 1987, Passos \& Sazima 1995, Riveros et al. 1995, Ree 1997).

O padrão de crescimento dos tubos polínicos de $S$. cinerea foi semelhante ao de outras espécies de Rubiaceae. Em flores brevistilas e longistilas autopolinizadas, os tubos pararam de crescer na superfície estigmática, sendo este mesmo resultado encontrado em espécies de Faramea (Bawa \& Beach 1983) e em Luculia gratissima (Wallich) Sweet (Murray 1990). No cruzamento entre flores longistilas de $S$. cinerea, alguns poucos tubos polínicos cresceram até a região mediana do estilete, ocorrendo diminuição do diâmetro e da intensidade da fluorescência, assim como a formação de "plugs" de calose mas, na maioria dos grãos, os tubos pararam de crescer ainda na superfície estigmática. O mesmo resultado, para os cruzamentos entre flores longistilas, foi observado em Cephaelis elata e Coussarea sp. (Bawa \& Beach 1983), Manettia luteo-rubra (Passos \& Sazima 1995) e em Psychotria barbiflora DC. (L.A.G. Teixeira \& I.C. Machado, dados não publicados). Apesar de não ter havido a verificação do local da reação de incompatibilidade entre flores brevistilas de agrupamentos distintos, possivelmente o resultado seria semelhante, não havendo o desenvolvimento dos tubos além do estilete, levando-se em consideração que os tubos pararam de crescer na superfície estigmática de flores brevistilas autopolinizadas. Possivelmente, os tubos polínicos atingiram o ovário das flores brevistilas depois de 12 horas da polinização, devido ao menor comprimento do estilete, o que nas flores longistilas só aconteceu após 24 horas decorridas da polinização. Segundo Bawa \& Beach (1983), de 10 espécies estudadas de Rubiaceae em que as flores brevistilas foram autopolinizadas, nove apresentaram a reação de incompatibilidade na superfície estigmática. O local da reação de incompatibilidade, nas espécies heterostílicas, é variável, ocorrendo na superfície estigmática, estilete ou, até mesmo, no ovário, podendo, nos dois morfos florais, essa reação ocorrer em locais diferentes, sendo o estigma o local mais comum nas flores brevistilas autopolinizadas (Gibbs 1986, 1990). Em alguns casos, os tubos oriundos de autopolinizações e polinizações intramorfos penetram na base do estilete, entretanto não ocorre a formação de sementes (Barrett \& Richards 1990). O sistema de autoincompatibilidade esporofítico em espécies distílicas comumente mostra a inibição de tubos polínicos incompatíveis no estigma (Ganders 1979, Bawa \& Beach 1983, Gibbs 1990) sendo, esse padrão, observado para $S$. cinerea.

Os resultados dos experimentos para verificação do sistema reprodutivo e do crescimento dos tubos polínicos confirmaram que Sabicea cinerea é autoincompatível, só havendo a formação de frutos através dos cruzamentos intermorfo. De acordo com a classificação de Cruden (1977), o resultado obtido na razão pólen-óvulo indica xenogamia facultativa para a espécie, o que não foi comprovado com os testes de polinizações controladas e pela verificação do crescimento dos tubos polínicos, mostrando xenogamia obrigatória. Os testes de polinizações manuais, em campo, mostraram que o sucesso na formação de frutos, nos cruzamentos intermorfos, foi semelhante sugerindo o equilíbrio do sistema heterostílico distílico de $S$. cinerea. Entretanto, nas flores utilizadas como controle, a formação de frutos foi um pouco maior nas brevistilas, podendo este resultado estar relacionado à formação de uma barreira na superfície estigmática ("clogging") das flores longistilas, o que impossibilitaria ou diminuiria a germinação dos grãos de pólen compatíveis. Essa barreira pode ter sido formada, principalmente, pela maior exposição do estigma das flores longistilas e, possivelmente, devido ao grande número de animais pilhadores observados nesses indivíduos. Como os agrupamentos longistílicos foram maiores em área, conseqüentemente o número mais elevado de flores abertas durante o dia contribuiu mais fortemente na atração dos animais em busca de recursos, principalmente o néctar e, dessa forma, podendo ter aumentado a deposição de grãos de pólen incompatíveis na superfície estigmática, promovendo a geitonogamia e "clogging" (sensu Webb \& Lloyd 1986), diminuindo o percentual de frutos formados naturalmente. Outro fato que pode ser questionado é a rota que alguns animais faziam para a coleta de néctar, principalmente o beijaflor Phaethornis ruber, o polinizador mais freqüente que, na maioria das vezes, visitava primeiro todas as flores de um dos agrupamentos longistílicos e, em seguida, todas as flores brevistílicas próximas, podendo o próprio ter contribuído para a deposição de pólen incompatível nas flores longistilas.

Com relação aos visitantes florais de $S$. cinerea, através das observações de comportamento e freqüência, pode-se dizer que o beija-flor Phaethornis ruber foi um dos principais polinizadores, principalmente por apresentar eficiência no transporte de pólen entre os morfos florais, contactando as estruturas sexuais das 
flores com regiões distintas do bico, e por ter sido bastante freqüente desde a abertura floral até o final do dia durante todo o ano. A alta freqüência de visitas do beija-flor $P$. ruber durante o dia pode ser atribuída às pequenas quantidades de néctar produzidas por flor, levando o animal a visitar muitas flores, várias vezes, no intuito de suprir suas necessidades energéticas. O beijaflor Amazilia sp. foi observado apenas em um dos agrupamentos longistílicos, apresentando comportamento territorialista, ficando pousado em um galho próximo e demonstrando agressividade com outros beija-flores que tentavam se aproximar das flores. De acordo com este comportamento, Amazilia sp. foi considerado pilhador, uma vez que não foi observado visitando as flores de indivíduos brevistílicos próximos e, possivelmente, promovendo o acúmulo de grãos incompatíveis no estigma das flores longistilas.

As espécies de borboletas e mariposas diurnas, muito freqüentes no pico de floração, possuem um aparelho bucal bastante comprido, aparentemente facilitando o contato com as anteras e estigmas durante a coleta do néctar. Dentre as espécies de abelhas Exaerete smaragdina pode ser considerada um importante polinizador, por ter realizado várias visitas durante o dia, nos dois morfos florais, e pela longa probóscide, adaptada à coleta de néctar de flores tubulosas sendo direcionada ao contato com as estruturas sexuais das flores. As outras espécies de abelhas, apesar de apresentarem um aparelho bucal longo, não foram muito freqüentes. De uma forma geral, a maioria foi observada com maior freqüência no período da manhã, fato que pode estar diretamente relacionado com a produção de néctar, apesar de Phaethornis ruber ter visitado as flores até o final da tarde, período em que o volume de néctar, produzido por flor, era menor.

As flores de $S$. cinerea também foram atrativas para um grande número de pilhadores, como as moscas, que aproveitaram o acúmulo do néctar em algumas flores longistilas, e as espécies de abelhas Xylocopa suspecta e Pseudoaugochloropsis sp., que coletaram néctar por fora do tubo floral através de uma fissura feita pelas mandíbulas. Da mesma maneira, Trigona fulviventris também foi considerada como pilhadora, uma vez que apenas coletava pólen das flores brevistilas, o que era facilitado pelo posicionamento das anteras no início da abertura do tubo floral.

Diante dos resultados, fica clara a importância dos polinizadores de Sabicea cinerea, principalmente porque esta espécie é autoincompatível, dependendo inteiramente desses animais na dispersão de pólen entre os morfos, os quais garantem o sucesso reprodutivo da espécie e, conseqüentemente, a manutenção do sistema heterostílico. Apesar da espécie estar em um fragmento florestal, dentro do centro urbano da cidade do Recife, PE, o sucesso reprodutivo está diretamente relacionado com a permanência dos polinizadores na área. Por outro lado, $S$. cinerea, por possuir um padrão de floração contínuo, representa uma importante fonte alimentar durante $o$ ano inteiro para os animais que se alimentam de néctar e de pólen.

Agradecimentos - A Ariadna Valentina Lopes, Paulo Eugênio Oliveira e Clemens Schlindwein pelas sugestões ao manuscrito, Ana Emília e Reginaldo na utilização do microscópio de fluorescência, Oscar Teixeira Basto Jr., Isa Leite, Ana Virgínia Leite e Cleci Neves pela ajuda no campo, Daniela Zappi pela identificação de Sabicea e André Santos, Antônio Aguiar e Tarcila Nadia pelos cálculos estatísticos. Ao CNPq pelo apoio financeiro com a bolsa de Mestrado ao primeiro autor e bolsa de produtividade em pesquisa ao segundo.

\section{Referências bibliográficas}

ANDERSSON, W.R. 1973. A morphological hypothesis for the origin of heterostyly in the Rubiaceae. Taxon 22:537-542.

BAKER, H.G. 1975. Sugar concentrations in nectars from hummingbird flowers. Biotropica 7:37-41.

BARRETT, S.C.H. 1992. Heterostylous genetic polymorphisms: model systems for evolutionary analysis. In Evolution and function of heterostyly. Monographs on theorical and applied genetics. (S.C.H. Barrett, ed.). Springer-Verlag, Berlin, p.1-24.

BARRETT, S.C.H. \& RICHARDS, J.H. 1990. Heterostyly in tropical plants. Memoirs of the New York Botanical Garden 55:35-61.

BAWA, K.S. \& BEACH, J.H. 1983. Self-incompatibility systems in the Rubiaceae of a tropical lowland wet forest. American Journal of Botany 70:1281-1288.

CASTRO, C.C. \& OLIVEIRA, P.E.A.M. 2002. Pollination Biology of distylous Rubiaceae in the Atlantic Rain Forest, SE Brazil. Plant Biology 4:640-646.

CONTRERAS, P.S. \& ORNELAS, J.F. 1999. Reproductive conflicts of Palicourea padifolia (Rubiaceae) a distylous shrub of a tropical cloud forest in Mexico. Plant Systematics and Evolution 219: 225-241.

COUTINHO, R.Q., LIMA, M.F., NETO, J.B.S. \& SILVA, E.P. 1998. Características climáticas, geológicas, geomorfológicas e geotécnicas da Reserva Ecológica de Dois Irmãos. In Reserva Ecológica de Dois Irmãos: Estudos em um remanescente de Mata Atlântica em área urbana. (I.C. Machado, A.V. Lopes \& K.C. Porto, eds). Secretaria de Ciência, Tecnologia e Meio Ambiente/ Editora Universitária-Universidade Federal de Pernambuco, Recife, p.21-50. 
CRUDEN, R.W. 1977. Pollen-ovule ratios: a conservative indicator of breeding systems in flowering plants. Evolution 31:32-46.

DARWIN, C.R. 1896. The different forms of flowers on plants of the same species. D. Aplleton and Company, New York.

DULBERGER, R. 1992. Floral polymorphisms and their functional significance in the heterostylous syndrome. In Evolution and function of heterostyly. Monographs on theorical and applied genetics (S.C.H. Barrett, ed.). Springer-Verlag, Berlin, p.41-84.

ENDRESS, P.K. 1994. Diversity and evolutionary biology of tropical flowers. Cambridge University Press, Cambridge.

ERDTMAN, G. 1966. Pollen morphology and plant taxonomy - Angiosperms. Hafner, New York.

FAEGRI, K. \& PIJL, L. VAN DER 1979. The principles of pollination ecology. Pergamon Press, London.

FEINSINGER, P. \& BUSBY, W.H. 1987. Pollen carryover: experimental comparisons between morphs of Palicourea lasiorrachis (Rubiaceae), a distylous, birdpollinated, tropical treelet. Oecologia 73:231-235.

GANDERS, F.R. 1979. The biology of heterostyly. New Zealand Journal of Botany 17:607-635.

GENTRY, A.H. 1974. Flowering phenology and diversity in tropical Bignoniaceae. Biotropica 6:64-68.

GIBBS, P. 1986. Do homomorphic and heteromorphic selfincompatibility systems have the same sporophytic mechanism? Plant Systematics and Evolution 154:285-323.

GIBBS, P. 1990. Self-incompatibility in flowering plants: a neotropical perspective. Revista Brasileira de Botânica 13:125-136.

GRANTSAU, R. 1989. Os beija-flores do Brasil. Editora Expressão e Cultura, Rio de Janeiro.

HAMILTON, C.W. 1990. Variations on a distylous theme in Mesoamerican Psychotria subgenus Psychotria (Rubiaceae). Memoirs of the New York Botanical Garden 55:62-75.

HERRERA, C.M. 1996. Floral traits and plant adaptation to insect pollinators: a devil's advocate approach. In Floral Biology: studies on floral evolution in animal-pollinated plants (D.G. Lloyd \& S.C.H. Barrett, eds.). Chapman \& Hall, New York, p.65-87.

HICKS, D.J., WYATT, R. \& MEAGHER, T.R. 1985. Reproductive biology of distylous partridgeberry, Mitchella repens. American Journal of Botany 72:1503-1514.

JUNG-MENDAÇOLLI, S. \& MELHEM, T. 1995. Grãos de pólen de espécies heterostílicas de Rubiaceae. Revista Brasileira de Botânica 18:61-93.

KEEGAN, C.R., VOSS, R.H. \& BAWA, K.S. 1979. Heterostyly in Mitchella repens (Rubiaceae). Rhodora 81:567-573.

KOHN, J.R. \& BARRETT, S.C. 1992. Experimental studies on the functional significance of heterostyly. Evolution 46:43-55.
MABBERLEY, D.J. 1993. The Plant-Book. A portable dictionary of the higher plants. Cambridge University Press, New York.

MACHADO, I.C. \& LOIOLA, I. 2000. Fly pollination and pollinator sharing in two synchronopatric species: Cordia multispicata (Boraginaceae) e Borreria alata (Rubiaceae). Revista Brasileira de Botânica 23:305-311.

MAÊDA, J.M. 1985. Manual para uso da câmara de Neubauer para contagem de pólen em espécies florais. Universidade Federal Rural do Rio de Janeiro, Rio de Janeiro.

MARTIN, F.W. 1959. Staining and observing pollen tubes in tile style by means of fluorescence. Stain Technology 34:125-128.

MURRAY, B.G. 1990. Heterostyly and pollen-tube interactions in Luculia gratissima (Rubiaceae). Annals of Botany 65:691-698.

NEWSTRON, L.E., FRANKIE, G.W. \& BAKER, H.G. 1994. A new classification for plant phenology based on flowering patterns in Lowland Tropical Rain Forest Trees at La Selva, Costa Rica. Biotropica 26:141-159.

ORTIZ, P.L., ARISTA, M. \& TALAVERA, S. 2000. Pollination and breeding system of Putoria calabrica (Rubiaceae), a Mediterranean dwarf shrub. Plant Biology 2:325-330.

PAILLER, T. \& THOMPSON, J.D. 1997. Distyly and variation in heteromorphic incompatibility in Gaertnera vaginata (Rubiaceae) endemic to La Reunion Island. American Journal of Botany 84:315-327.

PASSOS, L. \& SAZIMA, M. 1995. Reproductive biology of the distylous Manettia luteo-rubra (Rubiaceae). Botanica Acta 108:309-313.

PERCIVAL, M. 1965. Floral Biology. Pergamon Press, London.

PERCY, D.M. \& CRONK, Q.C.B. 1997. Conservation in relation to mating system in Nesohedyotis arborea (Rubiaceae), a rare endemic tree from St Helena. Biological Conservation 80:135-145.

PROCTOR, M., YEO, P. \& LACK, A. 1996. The natural history of pollination. Harper Collins, London.

RADFORD, A.E., DICKINSON, W.C., MASSEY, J.R. \& BELL, C.R. 1974. Vascular plant systematics. Harper \& Row, New York.

REE, R.H. 1997. Pollen flow, fecundity, and the adaptive significance of heterostyly in Palicourea padifolia (Rubiaceae). Biotropica 29:298-308.

RICHARDS, J.H. \& KOPTUR, S. 1993. Floral variation and distyly in Guettarda scabra (Rubiaceae). American Journal of Botany 80:31-40.

RIVEROS, G.M., BARRIA, O.R. \& HUMAÑA, A. 1995. Selfcompatibility in distylous Hedyotis salzmannii (Rubiaceae). Plant Systematics and Evolution 194:1-8.

SICK, H. 1985. Ornitologia Brasileira. Nova Fronteira, Rio de Janeiro. 
SOBREVILA, C., RAMIREZ, N. \& ENRECH, N.X. 1983. Reproductive biology of Palicourea fendleri and Palicourea petiolaris (Rubiaceae), heterostylous shrubs of a Tropical Cloud Forest in Venezuela. Biotropica 15:161-169.

SOKAL, R.R. \& ROHLF, F.J. 1996. Biometry. W.H. Feeman and Company, New York.

VUILLEUMIER, B.S. 1967. The origin and evolutionary development of heterostyly in the angiosperms. Evolution 21:210-226.
WASER, N.M, CHITTKA, L., PRICE, M.V., WILLIAMS, N.M. \& OLLERTON, J. 1996. Generalization in pollination systems, and why it matters. Ecology 77:1043-1060.

WEBB, C.J. \& LLOYD, D.G. 1986. The avoidance of interference between the presentation of pollen and stigmas in Angiosperms II. Hercogamy. New Zealand Journal of Botany 24:163-178.

ZEISLER, M. 1938. Über die Abgrenzung der eigentlichen Narbenfläche mit Hilfe von Reaktionen. Beiheft zum Botanisches Zentralblatt 58:308-318. 